\title{
The Turnover of Phospholipids in the Psychrophilic Bacterium Micrococcus cryophilus during Adaptation to Changes in Growth Temperature
}

\author{
By LINDA MCGIBBON AND NICHOLAS J. RUSSELL* \\ Department of Biochemistry, University College, PO Box 78, Cardiff CFI IXL, \\ South Wales, UK
}

(Received 18 February 1985; revised 2 May 1985)

\begin{abstract}
Cultures of Micrococcus cryophilus continue to grow without a lag following a sudden increase in temperature from $0{ }^{\circ} \mathrm{C}$ to $20^{\circ} \mathrm{C}$ (shift-up) or a reciprocal decrease (shift-down); the growth rate changes gradually to that typical of cultures grown isothermally at the final temperature. After a shift-down the phospholipid acyl chain length begins to change immediately, whereas there is a delay following a shift-up. However, the final fatty acid composition is attained within the same number of cell division times after a shift-up or shift-down. The changes in chain length after a shift-up or shift-down can be partially prevented by adding streptomycin or erythromycin at the time of the temperature shift. There is little or no turnover of the head-group or acyl chains of phospholipids during isothermal growth, at $0^{\circ} \mathrm{C}$ or $20^{\circ} \mathrm{C}$, nor after a shift-down. In contrast, after a shift-up approximately $40 \%$ of the phospholipid turns over during the first $12 \mathrm{~h}$ after the shift, but none during the subsequent $24 \mathrm{~h}$; phosphatidylglycerol turns over slightly faster than phospholipids during isothermal growth at $0^{\circ} \mathrm{C}$ or $20^{\circ} \mathrm{C}$, nor after a shift-down. In contrast, and acyl chains of each phospholipid. There is evidence for the conversion of phosphatidylglycerol to cardiolipin. It is argued that as a psychrophilic organism, well adapted to growth at low temperatures, $M$. cryophilus is more stressed by sudden increases of growth temperature than by a sudden decrease.
\end{abstract}

\section{INTRODUCTION}

Most poikilothermic organisms, including bacteria, modify their membrane lipid composition in response to changes in growth temperature. This is generally regarded as a mechanism to preserve membrane fluidity within certain limits (for reviews see McElhaney, 1976; Kates \& Kuksis, 1980; Quinn, 1981). In bacteria, which do not contain sterols in their membranes (Nes \& Nes, 1980; Harwood \& Russell, 1984), membrane fluidity is usually regulated by alterations in fatty acid composition. A number of different mechanisms are used, depending on the type of fatty acids present and the mode of fatty acid biosynthesis (Russell, 1984a); in some bacteria (e.g. bacilli, Fulco \& Fujii, 1980), but not in others (e.g. Escherichia coli, de Mendoza \& Cronan, 1983), enzyme induction is involved.

The psychrophilic bacterium Micrococcus cryophilus provides an example of phenotypic adaptation to changes in growth temperature that is particularly clear-cut, because it has a simple fatty acid composition - palmitoleic and oleic acids comprise $>95 \%$ of the total fatty acids - and as the bacterial growth temperature decreases from $20^{\circ} \mathrm{C}$ to $0{ }^{\circ} \mathrm{C}$ there is a fourfold decrease in the ratio $(\mathrm{C} 18 / \mathrm{Cl}$ ) of these two acids (Russell, 1971). There are no growthtemperature-dependent changes in fatty acid unsaturation. More recently we have shown that during isothermal growth the lower melting point $s n-1-18: 1, s n-2-16: 1$ phospholipid isomers are synthesized preferentially, and that this preference is maintained after a temperature shift despite the overall change in fatty acid chain length (McGibbon \& Russell, 1983). We have suggested that this may be an adaptation to the psychrophilic habit of growth of $M$. cryophilus.

Abbreviations: $\mathrm{C} 16: 0$, palmitic acid; $\mathrm{C} 16: 1$, palmitoleic acid; $\mathrm{C} 18: 0$, stearic acid; $\mathrm{C} 18: 1$, oleic acid; $\mathrm{C} 18 / \mathrm{C} 16$, ratio of (stearic acid + oleic acid)/(palmitic acid + palmitoleic acid). 
The fatty acid chain length change is mediated by a temperature-sensitive, membrane-bound elongase, which interconverts palmitate and stearate, via a myristate intermediate that is retained within the membrane environment (Sandercock \& Russell, 1980; Russell, 1984b). Since both the enzyme and the reactants remain in the membrane environment, membrane fluidity, as well as temperature directly, are likely to affect the activity of the enzyme. Although it has been shown that temperature has a direct effect on the products of fatty acid synthetase/elongase (Russell, 1984b), it has not been established whether the altered fatty acid products appeared in membrane phospholipids entirely by de novo phospholipid biosynthesis, or by acyl chain turnover too. $M$. cryophilus contains a phospholipase in its outer membrane (Lloyd \& Russell, 1984), which could be responsible for acyl chain turnover during temperature adaptation.

Phospholipid turnover has been investigated in relatively few bacterial species; these include Haemophilus influenzae (White \& Tucker, 1969), E. coli (Kanfer \& Kennedy, 1963; Kanemasa et al., 1967; Joselau-Petit \& Kepes, 1982), Salmonella typhimurium (Ames, 1968), Micrococcus cerificans (Makula \& Finnerty, 1971), Mycobacterium phlei (Akamatsu et al., 1967) and Streptomyces griseus (Verma et al., 1980). Each bacterial species has a unique pattern of phospholipid turnover, but the rates are usually slow; phosphatidylethanolamine is generally more stable than is phosphatidylglycerol, which has a complex metabolic interrelationship with several other membrane and cell wall components (Raetz, 1978; Harwood \& Russell, 1984). There may be pools of phosphatidylglycerol which are metabolically distinct (Joselau-Petit \& Kepes, 1982; Fulco, 1984). When phospholipid turnover has been investigated in sufficient detail it has been invariably complex, different parts of the individual phospholipids having quite different turnover rates (e.g. see White \& Tucker, 1969; Kanfer \& Kennedy, 1963; Kanemasa et al., 1967); in addition, particular molecular species may have different turnover rates (Kito et al., 1975). Apart from those in E. coli (Okuyama, 1969; Bright-Gaertner \& Proulx, 1972), there have been no studies of phospholipid turnover following changes in growth temperature - despite the large number of investigations in different species of growth temperature-dependent alterations in fatty acid composition. In terms of the biosynthetic mechanism of such changes, it is important that comparative studies should be undertaken so as to give insight into the more general phenomenon of phenotypic adaptation to temperature in bacteria.

We show in the present paper that in $M$. cryophilus there is no acyl chain turnover during isothermal growth, but that after a sudden change in growth temperature turnover does occur; the amount of turnover depends on whether the temperature is raised or lowered, and on how long after the shift it is measured. These results, and the question of whether enzyme induction is involved, are considered in the context of adaptation of $M$. cryophilus to growth at low temperatures.

\section{METHODS}

Maintenance and growth of hacteria. Micrococcus cryophilus ATCC 15174 was grown in a Casamino acids/salts medium, and maintained on the same medium solidified with $2 \%(w / v)$ agar (Russell, 1974). Cultures were grown at $0^{\circ} \mathrm{C}$ or $20^{\circ} \mathrm{C}$ in 50 or $800 \mathrm{ml}$ medium in $250 \mathrm{ml}$ or 2 litre Erlenmeyer flasks respectively, shaken at 120 r.p.m. in a refrigerated orbital shaker (Gallenkamp IH 465). Growth was estimated by measurement of $\mathrm{OD}_{600}$. The growth temperature in shift experiments was changed by centrifuging cultures at $10410 \mathrm{~g}\left(\mathrm{rav}_{\mathrm{as}} 9 \cdot 17 \mathrm{~cm}\right)$ for $10 \mathrm{~min}$ at $2^{\circ} \mathrm{C}$ or $20^{\circ} \mathrm{C}$ for cultures grown at $0^{\circ} \mathrm{C}$ and $20^{\circ} \mathrm{C}$ respectively, and resuspending the bacterial pellet in fresh medium at the appropriate temperature.

Extraction of lipids. Samples $(1 \mathrm{ml})$ of culture were added to $10 \mathrm{ml}$ chloroform/methanol $(1: 1, \mathrm{v} / \mathrm{v})$, mixed thoroughly and left at room temperature for $2 \mathrm{~h}$. Water $(3.5 \mathrm{ml})$ was added, and the suspension mixed and allowed to separate into two phases at $4{ }^{\circ} \mathrm{C}$. The lower, chloroform, phase containing the total lipids was removed with a Pasteur pipette. Further extraction and examination of the aqueous phase demonstrated that this method gave complete recovery of the lipids.

Fractionation of lipids. Total phospholipids were separated from the total lipid fraction by one-dimensional TLC on silica gel $\mathrm{H}$ (Merck) using light petroleum (b.p. $\left.60-80^{\circ} \mathrm{C}\right) /$ diethyl ether/glacial acetic acid $(85: 15: 1$, by vol.) as the solvent system. The total phospholipid fraction remained at the origin.

Individual phospholipid classes (phosphatidylethanolamine, phosphatidylglycerol and diphosphatidylglycerol) 
were separated by one-dimensional TLC on silica gel $\mathrm{H}$ using chloroform/methanol/glacial acetic acid/water $(170: 30: 20: 7$, by vol.) as the solvent system. Such separations were required for the determination of radioactivity in each phospholipid class. In order to aid the visualization of phospholipid spots on thin-layer chromatograms with iodine vapour, approximately $0.1 \mathrm{mg}$ carrier lipid (see Foot et al., 1983 for details) was added to the lipid samples before chromatography.

Measurement of acyl chain length. The acyl chain length of total lipids or total phospholipids was determined by GLC analysis of fatty acid methyl esters as described previously (Sandercock \& Russell, 1980). Samples of total lipid were evaporated to dryness before transmethylation, and the total phospholipid fraction was transmethylated directly by scraping the silica gel at the origin of TLC plates (see above) into transmethylation tubes (Foot et al., 1983). The acyl chain length is conveniently expressed as the ratio C18/C16 [i.e. $(\mathrm{C} 18: 0+$ $\mathrm{C} 18: 1) /(\mathrm{Cl} 16: 0+\mathrm{C} 16: 1)]$, calculated from the areas on chromatograms: in some experiments this was done automatically by electronic integration.

Fractionation of phospholipids into head-group and acy/chain moieties. Phospholipids were saponified by scraping the appropriate bands/spots into screwcap tubes, adding $2 \mathrm{ml} 10 \%(\mathrm{w} / \mathrm{v}) \mathrm{KOH}$ in methanol and heating at $70^{\circ} \mathrm{C}$ for $1 \mathrm{~h}$. The samples were cooled, diluted with $2 \mathrm{ml}$ water and acidified with conc. $\mathrm{HCl}$. The acyl chains, as unesterified fatty acids, were extracted with three $3 \mathrm{ml}$ volumes of light petroleum (b.p. $30-40{ }^{\circ} \mathrm{C}$ ) and transferred to a plastic scintillation vial. The solvent was evaporated, scintillant was added and the radioactivity was determined (see below).

The aqueous phase of the saponified mixture, containing the phospholipid head-groups, was transferred to a scintillation vial and dried overnight at $60^{\circ} \mathrm{C}$. Control experiments indicated that no significant loss of radioactivity occurred during this time. The dried residue was dissolved in $100 \mu \mathrm{l}$ water, scintillant was added and the radioactivity was determined.

Measurement of radioactivity. The radioactivity in total lipid extracts was determined by transferring the lower chloroform layer from extractions (see above) directly into a plastic scintillation vial. The solvent was evaporated and $5 \mathrm{ml}$ Fisofluor 2 (Fisons) scintillation cocktail added and the radioactivity measured with an LK B Rackbeta scintillation counter; a programmable facility for determination of quenching by the external standard ratio method was used to calculate counting efficiency. A standard curve was obtained using chloroform and an $\mathrm{n}-\left[\mathrm{U}^{1+} \mathrm{C}\right]$ hexadecane standard (Amersham).

The radioactivity in total or individual phospholipids was determined by scraping bands or spots on thin-layer chromatograms into scintillation vials and counting as above.

Measurement of phospholipid turnover. This was measured by a pulse-chase method. Exponential cultures were incubated at $0^{\circ} \mathrm{C}$ or $20^{\circ} \mathrm{C}$ with $185 \mathrm{kBq}$ sodium $[1-1+\mathrm{C}]$ acetate (Amersham; $2 \cdot 18 \mathrm{GBq} \mathrm{mmol}^{-1}$ ) for $10 \mathrm{~min}$, before centrifuging at $10410 \mathrm{~g}\left(r_{\mathrm{ar}} .9 .17 \mathrm{~cm}\right)$ for $10 \mathrm{~min}$. The bacterial pellet was resuspended in $50 \mathrm{ml}$ fresh growth medium (lacking radioactive acetate) at the appropriate temperature, depending on whether a temperature shift was required. At intervals duplicate samples $(1 \mathrm{ml}$ ) were removed for lipid extraction and fractionation (see above and figure legends for details of particular types of experiment), and the measurement of radioactivity.

In some experiments, particularly those in which the "chase" was at $20^{\circ} \mathrm{C}$, it was necessary to dilute the cultures to ensure that exponential growth was maintained. Allowance has been made for this dilution factor in the presentation of experimental data.

In order to check whether centrifugation and resuspension of bacteria in fresh growth medium caused artifactual phospholipid turnover, experiments were also done using an alternative protocol: instead of centrifuging cultures after the "pulse' time period with $\left[{ }^{1+} \mathrm{C}\right]$ acetate, a 1000 -fold excess of unlabelled acetate (approximately $2 \mathrm{~mm}$ final concentration) was added. When a temperature shift was also needed this was achieved in 2-3 min by swirling the flask under running tap-water at $20^{\circ} \mathrm{C}$ (for shift-up) or in ice-water (for shift-down). No differences in the experimental data from the two methods were detected.

\section{RESULTS}

When the growth temperature of $M$. cryophilus was altered suddenly from $20^{\circ} \mathrm{C}$ to $0{ }^{\circ} \mathrm{C}$ (shiftdown) cultures continued to grow without a lag but at a rate that gradually slowed to that of an isothermal $0{ }^{\circ} \mathrm{C}$ culture (Fig. 1). The phospholipid acyl chain length changed to a value typical of cultures grown isothermally at $0^{\circ} \mathrm{C}$ in 5-6 d (Fig. 1), and the $\mathrm{OD}_{600}$ increased two- to threefold. In separate experiments in which the $\mathrm{C} 18 / \mathrm{C} 16$ ratio was measured at intervals during the initial $12 \mathrm{~h}$ after the shift, no delay in its decrease was observed (data not shown).

In corresponding shift-up experiments, when the growth temperature was raised suddenly from $0{ }^{\circ} \mathrm{C}$ to $20^{\circ} \mathrm{C}$, cultures also continued to grow without a lag while the growth rate gradually increased to that of an isothermal $20^{\circ} \mathrm{C}$ culture (Fig. 2). However, in contrast to the shift-down experiments, there was a delay of 1-2 $\mathrm{h}$ before the change in phospholipid acyl chain length became apparent (Fig. 2). The acyl chain length of cultures reached a value characteristic of 


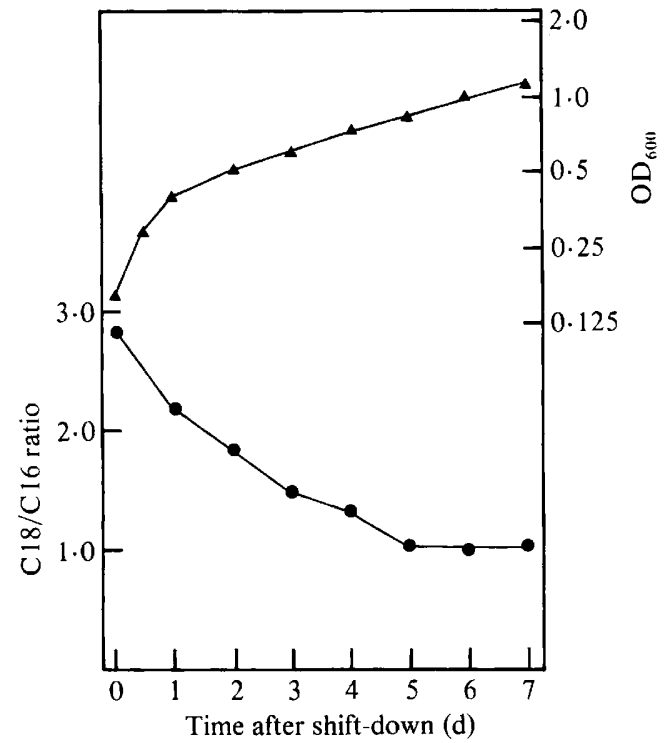

Fig. 1

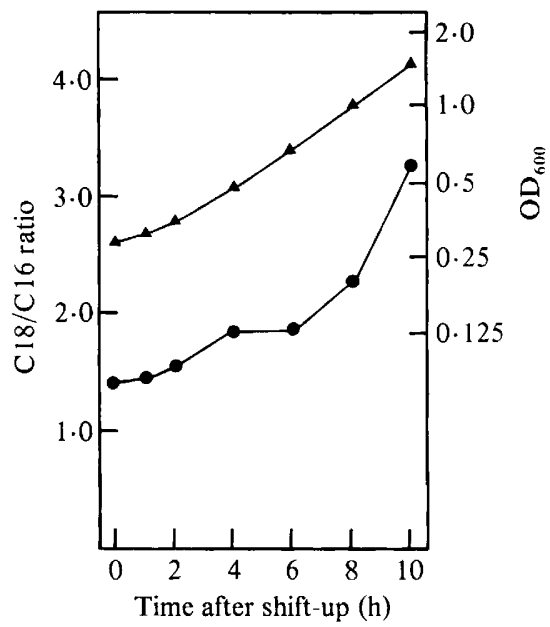

Fig. 2

Fig. 1. A culture growing exponentially at $20^{\circ} \mathrm{C}$ was centrifuged and resuspended in fresh growth medium at $0{ }^{\circ} \mathrm{C}$. Growth was monitored by measurements of $\mathrm{OD}_{600}(\boldsymbol{A})$. At intervals a sample was removed, total lipid extracted and total phospholipid fractionated by TLC; phospholipid acyl chain length was determined by GLC analysis, and is expressed as the ratio $\mathrm{C} 18 / \mathrm{C} 16(\mathrm{O})$.

Fig. 2. A culture growing exponentially at $0{ }^{\circ} \mathrm{C}$ was centrifuged and resuspended in fresh growth medium at $20^{\circ} \mathrm{C}$. Growth $(\boldsymbol{A})$ and phospholipid acyl chain length $(\boldsymbol{O})$ were measured as described in the legend to Fig. 1.

bacteria grown at $20^{\circ} \mathrm{C}$ in approximately $10 \mathrm{~h}$, and the $\mathrm{OD}_{600}$ increased two- to threefold. In both shift-up and shift-down experiments there were quite large (up to $20 \%$ ) variations between absolute values of $\mathrm{C} 18 / \mathrm{Cl}$ ratios of individual cultures, but the same time-course of acyl chain length changes was always observed, and representative experiments have been presented in Figs 1 and 2.

In both shift-down and shift-up experiments there were no differences in the time-courses of the chain length changes in the major phospholipids phosphatidylethanolamine and phosphatidylglycerol; the changes in diphosphatidylglycerol (cardiolipin) were slightly slower. There were no differences between the time-courses of the chain length changes of the $s n-1$ and $s n-2$ positions, and the longer average chain length of the $s n-1$ position relative to the $s n-2$ position was maintained (McGibbon \& Russell, 1983).

In order to determine whether the changes in chain length required concomitant protein synthesis and cell growth, antibiotics were used to inhibit these processes. The concentrations used were those necessary to just prevent growth, thus avoiding possible non-specific effects of higher concentrations. It was established first that the antibiotics did not alter the $\mathrm{C} 18 / \mathrm{C} 16$ ratio of cultures grown isothermally. Both streptomycin and erythromycin inhibited the changes in acyl chain length normally observed after a shift-down (Fig. $3 a$ ) or shift-up (Fig. 3b) in growth temperature. The inhibition was not always complete, and there were often small changes in chain length, particularly towards the later stages of an experiment; this may have been due to antibiotic inactivation but it was not investigated further.

The next stage in the investigation was to label phospholipids radioactively before determining the rates of phospholipid turnover. Sodium $\left[1-{ }^{14} \mathrm{C}\right]$ acetate was incorporated rapidly and with similar time-courses into both the head-group and acyl chains of phospholipids; in cultures growing isothermally at $20^{\circ} \mathrm{C}$ the incorporation into total phospholipid reached a steady-state after $10 \mathrm{~min}$ or less (Fig. 4). When the rate of labelling of individual phospholipids was measured it was found that the labelling of phosphatidylglycerol and phosphatidylethanol- 


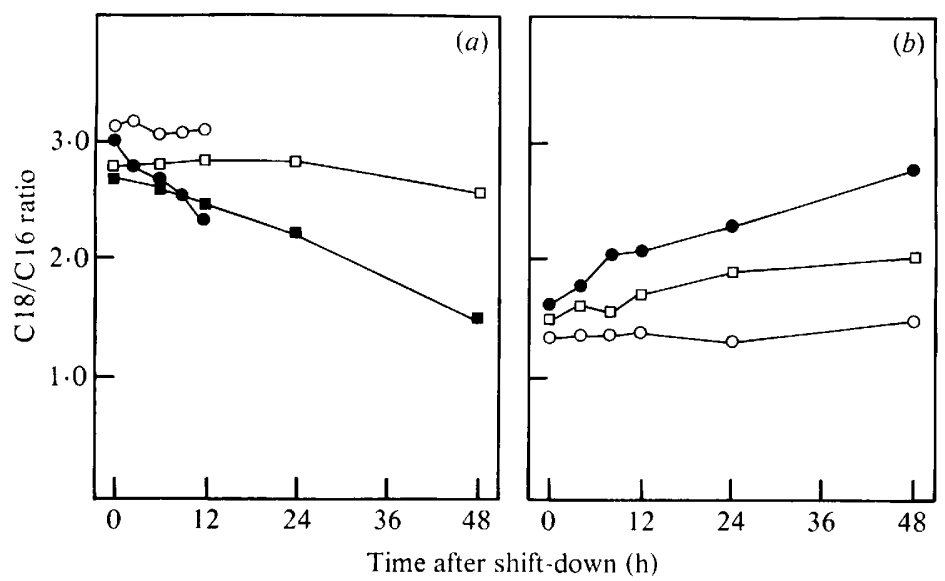

Fig. 3. (a) A culture growing exponentially at $20^{\circ} \mathrm{C}$ was centrifuged and resuspended in fresh growth medium at $0{ }^{\circ} \mathrm{C}$ containing erythromycin $\left(30 \mu \mathrm{g} \mathrm{ml}^{-1} ; \bigcirc\right)$ or streptomycin $\left(30 \mu \mathrm{g} \mathrm{ml}^{-1} ; \square\right)$; control cultures for the effects of erythromycin $(\bigcirc)$ or streptomycin $(\square)$ were resuspended in fresh growth medium lacking any antibiotic. At intervals samples were extracted, total phospholipid fractionated by TLC, and the phospholipid acyl chain length determined by GLC analysis. (b) A culture growing exponentially at $0^{\circ} \mathrm{C}$ was centrifuged and resuspended in fresh growth medium at $20^{\circ} \mathrm{C}$ containing erythromycin $(O)$, streptomycin $(\square)$ or no antibiotic $(\bigcirc)$ and the phospholipid acyl chain length determined as described in $(a)$ above.

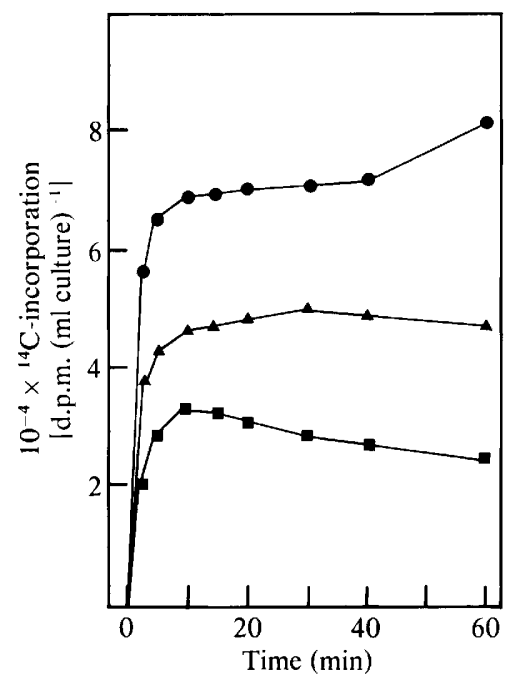

Fig. 4

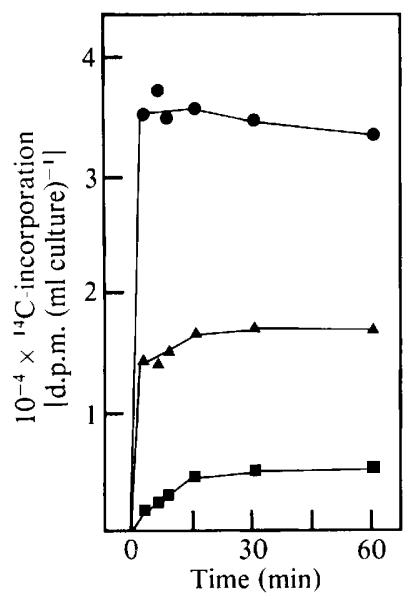

Fig. 5

Fig. 4. A culture growing exponentially at $20^{\circ} \mathrm{C}$ was incubated with sodium $[1-14 \mathrm{C}]$ acetate $\left(3.7 \mathrm{kBq} \mathrm{ml}^{-1}\right)$, and at intervals duplicate samples were extracted and the total phospholipids fractionated by TLC. One sample was counted directly to give ${ }^{14} \mathrm{C}$-incorporation into total phospholipids $(O)$. The other was saponified and the ${ }^{14} \mathrm{C}$-incorporation into head-group ( $\square$ ) and acyl chains ( $\mathbf{A})$ was measured.

Fig. 5. A culture growing exponentially at $20^{\circ} \mathrm{C}$ was incubated with sodium $\left[1^{-14} \mathrm{C}\right]$ acetate $\left(3.7 \mathrm{kBq} \mathrm{ml} l^{-1}\right)$ and at intervals samples were extracted, the individual phospholipids fractionated by TLC, and the ${ }^{14} \mathrm{C}$-incorporation into phosphatidylglycerol $(\boldsymbol{O})$, phosphatidylethanolamine $(\Delta)$ and diphosphatidylglycerol ( $\mathbf{Q})$ was measured.

amine was particularly rapid, reaching a steady-state in 1-2 min, whereas the labelling of diphosphatidylglycerol always lagged behind and reached a steady-state in $15 \mathrm{~min}$ (Fig. 5). An almost identical time-course was obtained using cultures growing isothermally at $0{ }^{\circ} \mathrm{C}$ (data not shown). Therefore, $10 \mathrm{~min}$ was chosen as the labelling time in subsequent isothermal, and shiftup or shift-down pulse-chase (turnover) experiments. 


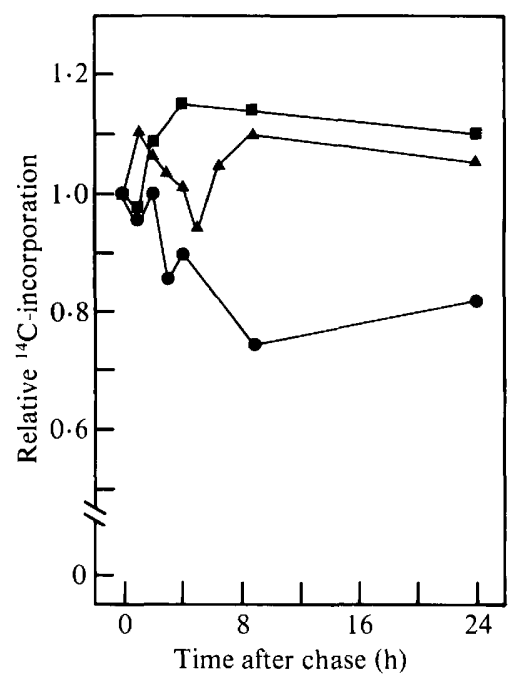

Fig. 6. A culture growing exponentially at $20^{\circ} \mathrm{C}$ was incubated with sodium $[1-1+\mathrm{C}]$ acetate $\left(3.7 \mathrm{kBq} \mathrm{ml} l^{-1}\right)$ for $10 \mathrm{~min}$, centrifuged and resuspended in fresh growth medium lacking radioactive acetate at $20^{\circ} \mathrm{C}$. At intervals samples were extracted, the individual phospholipids were fractionated by TLC, and the radioactivity in phosphatidylglycerol (O), phosphatidylethanolamine (A) and diphosphatidylglycerol ( $\mathbf{\square}$ ) was measured. Results are expressed as the radioactivity in samples relative to that in the initial sample, taken immediately after resuspension in non-radioactive fresh growth medium, which is given an arbitrary value of 1.0 .

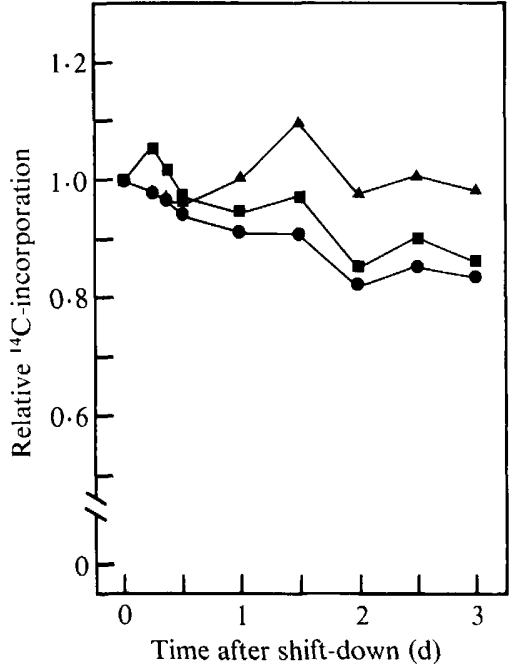

Fig. 7

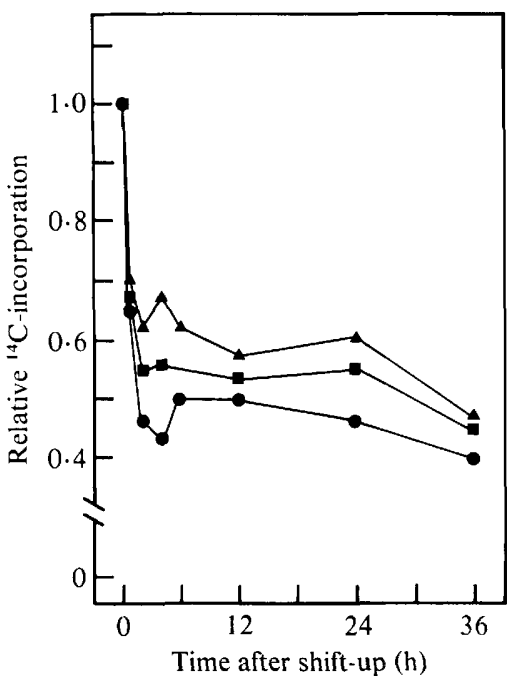

Fig. 8

Fig. 7. A culture growing exponentially at $20^{\circ} \mathrm{C}$ was incubated with sodium $[1-1+\mathrm{C}]$ acetate $\left(3.7 \mathrm{kBq} \mathrm{m}^{-1}\right)$ for $10 \mathrm{~min}$, centrifuged and resuspended in fresh growth medium lacking radioactive acetate at $0^{\circ} \mathrm{C}$. The radioactivity in phosphatidylglycerol $(\mathbf{O})$, phosphatidylethanolamine $(\boldsymbol{\Delta})$ and diphosphatidylglycerol ( $\square$ ) was measured, and is expressed as described in the legend to Fig. 6 .

Fig. 8. A culture growing exponentially at $0^{\circ} \mathrm{C}$ was incubated with sodium $[1-1+\mathrm{C}]$ acetate $\left(3.7 \mathrm{kBq} \mathrm{m} l^{-1}\right)$ for $10 \mathrm{~min}$, centrifuged and resuspended in fresh medium lacking radioactive acetate at $20^{\circ} \mathrm{C}$. The radioactivity in phosphatidylglycerol $(O)$, phosphatidylethanolamine $(\Delta)$ and diphosphatidylglycerol ( $\boldsymbol{\square}$ ) was measured, and is expressed as described in the legend to Fig. 6. 
Little or no turnover could be detected in cultures grown isothermally at $20^{\circ} \mathrm{C}$ when the total phospholipid was measured (data not shown). When individual phospholipids were investigated it was found that there was some turnover of phosphatidylglycerol, while the specific radioactivity of diphosphatidylethanolamine increased; there was no turnover of phosphatidylethanolamine (Fig. 6). The pattern was the same for the head-group and fatty acyl chain moieties of the phospholipids, and a similar result was obtained for cultures grown isothermally at $0{ }^{\circ} \mathrm{C}$ (data not shown).

When cultures were shifted-down from $20^{\circ} \mathrm{C}$ to $0{ }^{\circ} \mathrm{C}$, there was again little turnover of total phospholipid, the maximum value in different experiments being $10 \%$ during the first $24 \mathrm{~h}$ after the temperature shift (Fig. 7). When the major phospholipids were measured it was found that the specific radioactivity of phosphatidylglycerol and diphosphatidylglycerol decreased, while that of phosphatidylethanolamine was relatively constant (Fig. 7). Just as for isothermal growth, there was no difference in the behaviour of the head-group and fatty acyl chains (data not shown).

In contrast, a different result was obtained for the shift-up experiments. During the initial $12 \mathrm{~h}$ after the temperature shift approximately $40 \%$ of the total lipid was turned over, including both phosphatidylethanolamine and phosphatidylglycerol, with the latter being turned over at a slightly faster rate (Fig. 8). Both head-group and fatty acyl chain moieties were turned over at comparable rates (data not shown). There was no turnover of any phospholipid during the subsequent $24 \mathrm{~h}$ period (Fig. 8).

\section{DISCUSSION}

$M$. cryophilus grows over the temperature range $-4{ }^{\circ} \mathrm{C}$ to $+25^{\circ} \mathrm{C}$, and has been termed a psychrophile (Russell, 1974; Malcolm, 1969; Tai \& Jackson, 1969), although its optimum growth temperature of $21^{\circ} \mathrm{C}$ puts it outside the definition of Morita (1975) who would define it as a psychrotroph (Baross \& Morita, 1978). An alternative term is facultative psychrophile (compared with obligate psychrophile) using the definition of Ingraham \& Stokes (1959). However, there is no doubt that $M$. cryophilus is well adapted to growth at low temperatures: not only does it 'grow well at $0^{\circ} \mathrm{C}$ ' (i.e. it produces visible colonies within 1 week - definition of Stokes, 1963), but it can also cope with sudden increases or decreases in growth temperature that span the bulk of its growth temperature range, because it grows without a lag after such temperature shifts (Figs 1 and 2).

It has been argued previously that the membranes of $M$. cryophilus were adapted for growth at low temperature in that they contained a very high proportion of unsaturated fatty acids and the average chain length of these acids was altered in response to changes in growth temperature (Russell, 1971; 1984b) The preference for the lower melting point $s n$-1-long, sn-2-short phospholipid isomer would also favour growth at low temperatures, although this may well be more important in preventing too strong lipid-lipid interactions (McGibbon \& Russell, 1983). Changes in phospholipid isomer distribution, such as occur in Tetrahymena pyriformis (Dickens \& Thompson, 1982), are not part of the temperature adaptation mechanism in $M$. cryophilus.

The fact that the growth of $M$. cryophilus continued without a lag after a sudden shift in growth temperature (Figs 1 and 2) means that initially, after the shift, the bacteria grow with the 'wrong' fatty acid composition, indicating that the 'correct' fatty acyl chain length is not strictly necessary for growth at a particular temperature. However, the growth rate changed continuously during the adaptive period - i.e. the growth rate adapted while the fatty acid composition was modified - suggesting that growth rate and membrane fatty acyl composition are indeed closely matched.

Similarly, Hasegawa et al. (1980) showed that when the growth temperature of Bacillus caldotenax was changed from $65^{\circ} \mathrm{C}$ to $45^{\circ} \mathrm{C}$ the culture grew immediately, without a lag, and moreover with a generation time typical of cultures grown isothermally at $45^{\circ} \mathrm{C}$ even though the protein and lipid contents of $45^{\circ} \mathrm{C}$ cells were not achieved until one generation time after the temperature shift. In comparison, when $E$. coli is subjected to a sudden lowering of its growth temperature, it stops growing for several hours (Okuyama, 1969), despite the fact that modification of the fatty acyl chains of its membrane lipids begins within $30 \mathrm{~s}$ of the temperature 
shift (Garwin \& Cronan, 1980). It is clear from these two examples and that of $M$. cryophilus that different bacterial strains react differently to sudden changes in their growth temperature.

The fatty acyl chain length of $M$. cryophilus started to adjust immediately after a shift-down, but only after a lag following a shift-up; however, there was the same amount of growth, measured as a two- to threefold increase in $\mathrm{OD}_{600}$, in each instance (cf. Figs 1 and 2). Since $\mathrm{OD}_{600}$ corresponds to cell numbers (N. J. Russell, unpublished results), this means that the final fatty acyl composition was achieved within a comparable number of cell generations after shiftup or shift-down. That a delay in the onset of the chain length change occurred only after a shiftup can be interpreted in several ways. A sudden rise in temperature might stress the cells by causing a state of hyperfluidity in the membrane that could inhibit one of the enzymes of phospholipid biosynthesis, all of which are membrane bound (Raetz, 1978). The sudden temperature rise could cause a temporary loss of ATP or other essential compound(s), although membrane permeability does not normally increasae in $M$. cryophilus below $25^{\circ} \mathrm{C}$ (Malcolm, 1968).

The prevention of the acyl chain length change by erythromycin and streptomycin implies that cell growth and protein synthesis are necessary for modification of fatty acid composition. The mechanism could be by inhibition of synthesis either of the elongase per se, or of some other necessary component (e.g. ACP for an acyl-ACP substrate). Since inhibition was not complete, a component like ACP that is turned over rapidly might be involved. This argument applies to both the shift-down and shift-up responses, because the elongase can catalyse retroconversion i.e. fatty acid chain shortening from C1 8 to C16 (Russell, 1978; Sandercock \& Russell, 1980). In $M$. cryophilus the fatty acid elongase enzyme system is distinct from the fatty acid synthetase, as demonstrated by their differential sensitivity to cerulenin (Sandercock \& Russell, 1981), response to different precursors (Sandercock \& Russell, 1980) and sub-cellular fractionation (Russell, 1984b).

In order to distinguish between these alternatives, the biosynthesis and turnover of phospholipids were investigated, first in cultures growing isothermally, then in cultures subjected to a sudden shift in growth temperature. The use of $\left[{ }^{14} \mathrm{C}\right]$ acetate enabled the biosynthesis of both the head-group and fatty acyl chains to be determined from the same precursor. A steady state of phospholipid radioactive labelling was achieved within minutes, with that of diphosphatidylglycerol lagging behind that of phosphatidylglycerol and phosphatidylethanolamine; this probably reflects the fact that diphosphatidylglycerol is derived directly from two molecules of phosphatidylglycerol (De Siervo \& Salton, 1971; Hirschberg \& Kennedy, 1972; Short \& White, 1972). The similar rates of biosynthesis of the head-group and fatty acyl moieties from the single radioactive precursor implies a coordination in their biosynthesis, and is consistent with there being small phospholipid precursor pools in $M$. cryophilus such as has been shown for $E$. coli (Leduc \& Schaechter, 1978). Control experiments showed that at the concentrations of $\left[{ }^{14} \mathrm{C}\right]$ acetate used, transport of the precursor into bacteria was not a limiting factor, and a much lower than saturating concentration was used so as to prevent perturbation of cellular metabolism.

The similar incorporation rates of $\left[{ }^{1+} \mathrm{C}\right]$ acetate into phospholipids at $0{ }^{\circ} \mathrm{C}$ and $20^{\circ} \mathrm{C}$ might at first seem unexpected. However, a psychrophilic bacterium would be expected to have efficient low temperature transport and biosynthetic capabilities. The transport of lysine in $M$. cryophilus is just as rapid at $0{ }^{\circ} \mathrm{C}$ as at $20^{\circ} \mathrm{C}$ (Russell, 1971); similarly active transport systems at low temperatures have been demonstrated in several other psychrophilic bacteria (Herbert \& Bhakoo 1979), and this has been considered as one of the characteristics of psychrophilic organisms (Jay, 1978).

The pulse-chase experiments showed that during isothermal growth there was no turnover of the membrane phospholipids. The apparent turnover of phosphatidylglycerol almost certainly represented its conversion to diphosphatidylglycerol, the radioactivity of which increased during the chase (Fig. 6); this conclusion is supported by the observation that the radioactivity in the head-group and fatty acyl chain moieties of the phospholipids changed in concert.

The suggestion above that a shift-up stresses the cells more than a shift-down is supported by the results of the pulse-chase experiments which showed that phospholipid turnover occurred 
during the period immediately after a shift-up but not a shift-down (cf. Figs 7 and 8). The turnover was of the whole phospholipid molecule, not the fatty acyl chains alone. Although phospholipid turnover began immediately following the shift-up (Fig. 8), there was a delay of approximately $2 \mathrm{~h}$ before the $\mathrm{C} 18 / \mathrm{C} 16$ ratio of the fatty acids began to increase (Fig. 2). Thus it appears that the temperature response of the fatty acid synthetase/elongase enzymes lags behind that of phospholipid turnover, which must involve re-acylation with fatty acids of the same composition during the first $2 \mathrm{~h}$ after the shift-up. This may be because $M$. cryophilus uses elongation, rather than desaturation, to modify its fatty acid composition in response to temperature changes: fatty acyl chains can be desaturated in intact phospholipid molecules, whereas they must be removed for elongation at the carboxyl terminus. Immediate stimulation of phospholipid turnover by the raised temperature ensures that the average chain length of the phospholipids is increased as soon as the fatty acid synthetase/elongase system has adapted to the new temperature. This involvement of phospholipid turnover in shift-up but not shift-down mirrors the response of the fatty acid synthetase/elongase enzymes (as measured by phospholipid fatty acyl composition), which lags on shift-up but not shift-down - i.e. there is a delay in elongation but not in retroconversion. It seems unlikely that the $2 \mathrm{~h}$ lag in elongation is due to the lack of suitable enzymic protein because proteins are synthesized within a few minutes in bacteria (McQuillen, 1973). Since the same membrane-bound enzyme system catalyses elongation and retroconversion, it appears that a sudden increase in membrane fluidity is more inhibitory than a sudden decrease; this inhibition is superimposed on the direct effect of temperature on the elongase enzyme. Thus there is a complex interplay between direct effects of temperature and indirect effects of membrane fluidity, and the latter may well act as both cause and effect.

The net result of these complementary differences in the two aspects of phospholipid chain length changes is to produce similar overall time-courses (measured in terms of cell generation) for adaptation to increased or lowered temperature. Therefore the organism can cope with both kinds of temperature change, by having evolved a means not only of coping with low temperature growth but also a way of dealing with moderate increases in temperature. Both these would be experienced in its natural habitat in the soil and food.

\section{REFERENCES}

Akamatsu, Y.. Ono, Y. \& Nojima, S. (1967). Studies on the metabolism of phospholipids in Mycohacterium phlei. I. Difference in turnover rates of individual phospholipids. Journal of Biochemistry 61, 96102.

Ames, G. F. (1968). Lipids of Salmonella typhimurium and Escherichia coli: structure and metabolism. Journal of Bacteriolog. 95, 833-837.

Baross, J. A. \& Morita, R. Y. (1978). Microbial life at low temperatures: ecological aspects. In Microbial Life in Evtreme Encironments, pp. 9-71. Edited by D. J. Kushner. New York: Academic Press.

Bright-Gaertner, E. \& Proulx, P. (1972). Metabolism of phosphoglycerides in Escherichia coli during growth at $37^{\circ} \mathrm{C}$ and during a cold-induced lag phase. Biochimica et biophysica acta 270, 40-49.

De Siervo, A. J. \& Salton, M. R. J. (1971). Biosynthesis of cardiolipin in the membranes of Micrococcus lysodeikticus. Biochimica et biophysica acta 239, 280-292.

Dickens, B. F. \& Thompson, G. A., JR (1982). Phospholipid molecular species alterations in microsomal membranes as an initial step during cellular acclimation to low temperature. Biochemistry $\mathbf{2 1}$, 3604-3611.

FOOT, M., JefFCOAT, R. \& Russell, N. J. (1983). Some properties, including the substrate in vivo, of the 19 -desaturase in Mirrococcus cryophilus. Biochemical Journal 209, 345-353.

Fulco, A. J. (1984). Regulation and pathways of membrane lipid biosynthesis in bacilli. In Biomembranes, Vol. 12. Membrane Fluidity, pp. 303327. Edited by M. Kates \& L. A. Manson. New York: Plenum

Fulco, A. J. \& FujII, D. K. (1980). Adaptive regulation of membrane lipid biosynthesis in bacilli by environmental temperature. In Membrane' Fluidity. Biophysical Techniques and Cellular Regulation pp. 77-98. Edited by M. Kates \& A. Kuksis. New Jersey: Humana Press.

Garwin, J. L. \& Cronan, J. E., JR (1980). Thermal modulation of fatty acid synthesis in Escherichia coli does not involve de noro enzyme synthesis. Journal of Bacteriolog! 141, 14571459.

HaRWOOD, J. L. \& Russell, N. J. (1984). Lipids in Plants and Microhes, p. 26. London: George Allen \& Unwin.

Hasegawa, Y., Kawada, N. \& Nosoh, Y. (1980). Change in chemical composition of membrane of Bacillus caldotenax after shifting the growth temperature. Archices of Microbiology 126, 103-108.

Herbert, R. A. \& Bhakoo, M. (1979). Microbial growth at low temperatures. In Cold Tolerant Microbes in Spoilage and the Environment. Society for 
Applied Bacteriology. Technical Symposium no. 13, pp. 1-16. Edited by A. D. Russell \& R. Fuller. London: Academic Press.

HirschberG, C. B. \& KenNedy, E. P. (1972). Mechanism of the enzymatic synthesis of cardiolipin in Escherichia coli. Proceedings of the National Academy of Sciences of the United States of America 69, 648-65I.

Ingraham, J. L. \& Stokes, J. L. (1959). Psychrophilic bacteria. Bacteriological Reviews 23, 97-108.

JAY, J. M. (1978). Characteristics and growth of psychrophilic/psychrotrophic microorganisms. In Modern Food Microbiology, pp. 415-430. New York: Van Nostrand.

Joselau-Petit, D. \& KePes, A. (1982). Degraded and stable phosphatidylglycerol in Escherichia coli inner and outer membranes, and recycling of fatty acyl residues. Biochimica et biophysica acta 711, 1-9.

Kanemasa, Y., Akamatsu, Y. \& Nojima, S. (1967). Composition and turnover of phospholipids in Escherichia coli. Biochimica et biophysica acta 144, 382-390.

KANFER, J. \& KenNedy, E. P. (1963). Metabolism and function of bacterial lipids. I. Metabolism of phospholipids in Escherichia coli B. Journal of Biological Chemistry 238, 2919-2922.

Kates, M. \& Kuksis, A. (editors) (1980). Membrane Fluidity. Biophysical Techniques and Cellular Regulation. New Jersey: Humana Press.

Kito, M., Ishinaga, M., Nishihara, M., Kato, M., SAWADA, S. \& HaTA, T. (1975). Metabolism of the phosphatidylglycerol molecular species in Escherichia coli. European Journal of Biochemistry 54, 55-63.

LEDUC, M. \& SCHAECHTER, M. (1978). Size of the lipid precursor pool in Escherichia coli. Journal of Bacteriology 133, 1038.

LLOYD, G. M. \& RuSSEll, N. J. (1984). The isolation and characterisation of cytoplasmic and outer membranes from Micrococcus cryophilus. Canadian Journal of Microbiology 30, 1357-1366.

Makula, R. A. \& FinNeRTY, W. R. (1971), Microbial assimilation of hydrocarbons: phospholipid metabolism. Journal of Bacteriology 107, 806-811.

Malcolm, N. L. (1968). Synthesis of protein and ribonucleic acid in a psychrophile at normal and restrictive growth temperatures. Journal of Bacteriology 95, 1388-1399.

MalColm, N. L. (1969). Molecular determinants of obligate psychrophily. Nature, London 221, 10311033.

MCElhaney, R. N. (1976). The biological significance of alterations in fatty acid composition of microbial membrane lipids in response to changes in environmental temperature. In Extreme Environments: Mechanisms of Microbial Adaptation, pp. 255-281. Edited by M. R. Heinrich. New York: Academic Press.

McGibbon, L. \& Russell, N. J. (1983). Fatty acid positional distribution in phospholipids of a psychrophilic bacterium during changes in growth temperature. Current Microbiology 9, 241-244.

MCQuillen, K. (1973). Class III reactions: synthesis of proteins, Part II. In Biochemistry of Bacterial Growth, 2nd edn, pp. 332-333. Edited by J. Mandelstam \& K. McQuillen. London : Blackwell Scientific. de Mendoza, D. \& Cronan, J. E. JR (1983). Thermal regulation of membrane lipid fluidity in bacteria. Trends in Biochemical Sciences 8, 49-52.

Morita, R. Y.(1975). Psychrophilic bacteria. Bacteriological Reriews 39, 144-167.

NES, W. R. \& NES, W. D. (1980). Lipids in Evolution, pp. 97-155. New York: Plenum.

OkuYama, H. (1969). Phospholipid metabolism in Escherichia coli after a shift in temperature. Biochimica et biophysica acta 176, 125-134.

QuinN, P. J. (1981). The fluidity of cell membranes and its regulation. Progress in Biophysics and Molecular Biology 38, 1-104.

RAETZ, C. R. H. (1978). Enzymology, genetics, and regulation of membrane phospholipid synthesis in Escherichia coli. Microbiological Reviews 42, 614-659.

Russell, N. J. (1971). Alteration in fatty acid chain length in Micrococus cryophilus grown at different temperatures. Biochimica et biophysica acta 231, 254 256.

Russell, N. J. (1974). The lipid composition of the psychrophilic bacterium Micrococcus cryophilus. Journal of General Microbiolog. 80, 217-225.

Russell, N. J. (1978). The positional specificity of a desaturase in the psychrophilic bacterium Micrococcus cryophilus (ATCC 15174). Biochimica et biophysica acta 531, 179-186.

Russell, N. J. (1984a). Mechanisms of thermal adaptation in bacteria: blueprints for survival. Trends in Biochemical Science 9, 108-112.

Russell, N. J. (1984b). The regulation of membranes fluidity in bacteria by acyl chain length changes. In Biomembranes, Vol. 12, Membrane Fluidity, pp. 329347. Edited by M. Kates \& L. A. Manson. New York: Plenum.

SANDERCoCK, S. P. \& Russell, N. J. (1980). The elongation of exogenous fatty acids and the control of phospholipid acyl chain length in Micrococcus cryophilus. Biochemical Journal 188, 585-592.

Sandercock, S. P. \& Russell, N. J. (1981). The differential inhibition by cerulenin of fatty acid synthesis and elongation in the psychrophilic bacterium Micrococcus cryophilus. Biochemical Society Transactions 9, 60-61.

Short, S. A. \& White, D. C. (1972). The biosynthesis of cardiolipin from phosphatidylglycerol in Staphylococcus aureus. Journal of Bacteriology 109 , $820-826$.

StOKES, J. L. (1963). General biology and nomenclature of psychrophilic microorganisms. In Recent Progress in Microbiology. 8th Symposium of the International Congress of Microbiology, Montreal, 1962, pp. 187-192. Edited by N. E. Gibbons. Toronto: University of Toronto Press.

TAI, P. C. \& JACKSON, H. (1969). Mesophilic mutants of an obligate psychrophile, $M$. cryophilus. Canadian Journal of Microbiology 15, 1145-1150.

Verma, J. N., Khera, A., Khuller, G. K. \& Subramanyan, D. (1980). Phosphoglyceride metabolism in Streptomyces griseus. Current Microbiology 4, 13-15.

White, D. C. \& Tucker, A. N. (1969). Phospholipid metabolism during bacterial growth. Journal of Lipid Research 10, 220-233. 